\title{
Attitudes and Perceptions of Medical Students toward Neurosurgery as a Career, Riyadh, Saudi Arabia
}

\author{
Nayef Ghasham AlQahtani ${ }^{1}$, Turki Alhumaid ${ }^{1}$, Khalid Almazyad ${ }^{1}$, Ibrahim Almesned ${ }^{1}$, \\ Abdulaziz Almusalam ${ }^{1}$, Sajida Agha ${ }^{2}$ \\ ${ }^{1}$ King Saud Bin Abdulaziz University for Health Sciences, College of Medicine, Riyadh, Saudi \\ Arabia. ${ }^{2}$ King Saud Bin Abdulaziz University for Health Sciences, Medical Education, Riyadh, Saudi \\ Arabia
}

Corresponding Author: Nayef Ghasham AlQahtani, Phone: 00966541900031, Email: naif50501@ hotmail.com

\begin{abstract}
Introduction: Medical students usually show a preference toward a specific specialty. They could have the preference before entering the medical school but their preference could change. There has been a decline in surgical specialty as a career choice by medical students more recently. The objective of the study is to evaluate the attitude and perception of medical students toward neurosurgery. Methods and Materials: This is a cross-sectional study that was conducted in King Saud Bin Abdulaziz University for health sciences in RIYADH, SAUDI ARABIA on 218 medical students from the fifth and sixth year, using a validated questionnaire comprising of 15 questions with a scoring based on Linkert ranking scale (1, disagree; 2, agree somewhat; 3, agree moderately; 4, agree Strongly). Results: The distribution response was 85\%, only 186 (102 males vs. 84 females) medical students completed the questionnaire. The data shows that the majority of students think that their neurosurgery teaching is inadequate, neurosurgical history is difficult to obtain, neurosurgical signs are difficult to elicit and that most of them $86 \%$ aren't considering neurosurgery as a future career because it can impede family life. Conclusion: This study point out some areas that can be targeted and improved to enhance the student's perception of neurosurgery as a specialty and to facilitate learning of neurosurgery knowledge during medical school. Also, a study on a larger sample might be required to generalize the results.
\end{abstract}

Keywords: Neurosurgery, Career choice, Medical Students attitude, Working time, Surgical training, Linkert scale

\section{INTRODUCTION}

Medical students usually show a preference toward a specific specialty. They could have the preference before entering the medical school but their preference could change. During or near the end of clinical years, students have tried most of the major specialties like internal medicine, General surgery, Pediatric, obstetrics and gynecology etc. And have acquainted the nature and working environment of each specialty, so now they have better visualization and more transparent idea of what they want. Recently there has been a propensity toward nonsurgical specialties as a career choice by medical students, which is a concern ${ }^{1}$.
There are many factors which may contribute to medical students' deviation away from surgical specialties like surgeons' life style, long working hours, family pressure and financial income compared to the working hour requirements. Another factor is that the number of female medical students has greatly increased recently which have also contributed to this trend. In one study they found out that females are less likely than males to join a surgical training program ${ }^{2}$. In the same study students have designated working hour limitations a higher priority than Future income, however, $86 \%$ of students said that the most important factor in choosing a residency program is intellectual interest ${ }^{2}$.

Surgical training is not only a science 
but also an art. Surgical training requires dedication and passion the reason for that is that it requires a long period of training. In one study they estimated the average total time for operative training to be 3963 hours $^{3}$. Most of the training period is spent as a chief surgeon with an average of 2753 hours $^{3}$. Surgical residency programs remain the most time consuming among other programs ${ }^{2}$. This fact is concerning because medical students are less likely to choose time-demanding specialty ${ }^{4}$. In a study conducted in The Royal College of Surgeons in Ireland on third, fourth and fifth year medical students to evaluate the attitudes and perceptions of medical student toward neurosurgery ${ }^{5}$. The results have shown that majority of students found that neurosurgery history is difficult to obtain and the signs are difficult to identify. Their training was inadequate, the diseases have poor prognosis and the neurosurgery residency program is long ${ }^{5}$.

MATERIALS AND METHODS: This study was conducted at King Saud bin Abdulaziz University for Health Sciences, college of medicine, RIYADH, SAUDI ARABIA from March 2018 to May 2018. This cross-sectional study included 218 male and female medical students from fifth and sixth year to evaluate their attitudes and Perceptions toward Neurosurgery. After signing consent, they were asked to fill out a questionnaire. Participants with incomplete questionnaire were excluded from the study.

This study was conducted using a Questionnaire comprising of 15 questions with a scoring based on Linkert Ranking Scale (1, disagree; 2, agree somewhat; 3, agree moderately; 4, agree strongly). This questionnaire has been validated and used in international studies that have been published. Demographic information was collected to compare the results. After ethical approval from College of medicine and then from KAIMRC (King Abdullah International Medical Research Center), the questionnaire was distributed in the class during PBLsession after informed consent was taken. Confidentiality of the information was assured. Data was entered using Microsoft Excel and was exported to SPSS (V21) for analysis. Data was presented as frequency and percentages (\%) and reported based on Linkert Scale.

\section{Results}

In this study 218 medical students were included from fifth and sixth year, but only 186 students (102 males and 84 females) completed the questionnaire, so the distribution response was $85 \%$. Mean age of participants was 22.82 years (Range, 20-29 years) Figure 1A. Standard deviation 2.09. $97 \%$ of participants are single while $3 \%$ are married (180 single Vs. 6 married) Figure 1B. $55 \%$ of participants were males and $45 \%$ were females (102 males Vs. 84 females) Figure 1C. 58\% of the participants were from fifth year while $42 \%$ of the participants were from sixth year (108 fifth year Vs. 78 Sixth year) Figure 1D. Results of Linkert Scale are presented in Figure 2, 3 and Table 1. 87\% of students agreed that their neurosurgery teaching is inadequate while around 13\% believe the opposite. Around 94\% of the participants believed that neurosurgical history is difficult to obtain and that neurosurgical signs are difficult to elicit. Of the respondents $91 \%$ believe that neurosurgical illnesses are complicated and difficult. There was an agreement $>95.3 \%$ of the respondents that neurosurgery requires long operating hours and a long training period, and $93 \%$ believed that neurosurgery training in Saudi Arabia is too prolonged. Of respondents around 93\% acknowledge high prestige and income are attached to neurosurgery. However, 97.8\% believe that neurosurgery can impede family life and only $14 \%$ consider neurosurgery an option for future career. 


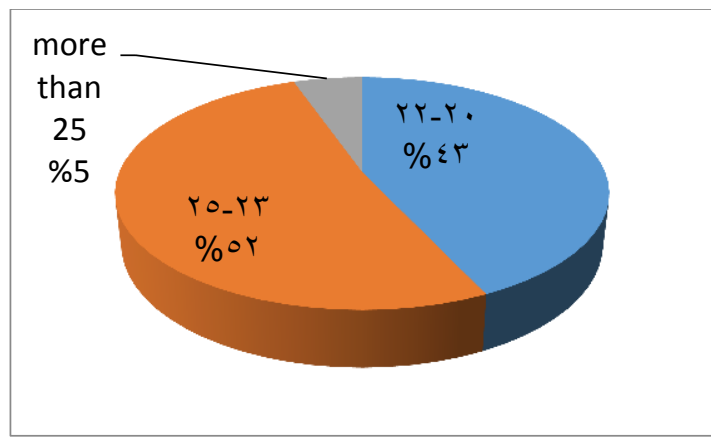

Figure 1A. Age of Participants

Figure 1C Gender of participants.

Table 1 Items on Linker scale

\begin{tabular}{|c|c|c|c|}
\hline & & Disagree & agree(likert2-4) \\
\hline 1 & My neurosurgery teaching is inadequate & $23(12.4 \%)$ & $163(87.6 \%)$ \\
\hline 2 & I consider neurosurgery as a career option & $160(86 \%)$ & $26(14 \%)$ \\
\hline 3 & Neurosurgical history is difficult to obtain & $12(6.5 \%)$ & $174(93.5 \%)$ \\
\hline 4 & Neurosurgical signs are difficult to elicit & $11(5.9 \%)$ & $175(94.1 \%)$ \\
\hline 5 & Limited interventions are available in neurosurgery & $42(22.6 \%)$ & $144(77.4 \%)$ \\
\hline 6 & Neurosurgical illnesses are complicated and difficult & $17(9.1 \%)$ & $169(90.9 \%)$ \\
\hline 7 & $\begin{array}{l}\text { Neurosurgical illnesses } \text { are challenging and } \\
\text { interesting }\end{array}$ & $86(46.2 \%)$ & $100(53.8 \%)$ \\
\hline 8 & Most neurosurgical illnesses have poor outcomes & $47(25.3 \%)$ & $139(74.7 \%)$ \\
\hline 9 & Neurosurgery requires a long training period & $8(4.3 \%)$ & $178(95.7 \%)$ \\
\hline 10 & Neurosurgery requires long operating hours & $5(2.7 \%)$ & $181(97.3 \%)$ \\
\hline 11 & $\begin{array}{l}\text { Huge prestige and income are attached to } \\
\text { neurosurgery }\end{array}$ & $14(7.5 \%)$ & $172(92.5 \%)$ \\
\hline 12 & Neurosurgery can impede family life & $4(2.2 \%)$ & $182(97.8 \%)$ \\
\hline 13 & $\begin{array}{l}\text { Neurosurgery training in Saudi Arabia is too } \\
\text { prolonged }\end{array}$ & $13(7 \%)$ & $173(93 \%)$ \\
\hline 14 & $\begin{array}{l}\text { Neurosurgical training centers in Saudi Arabia are } \\
\text { few }\end{array}$ & $152(81.7 \%)$ & $34(18.3 \%)$ \\
\hline 15 & $\begin{array}{l}\text { Future job opportunities in Saudi Arabia will be } \\
\text { limited }\end{array}$ & $23(12.4)$ & $163(87.6 \%)$ \\
\hline
\end{tabular}

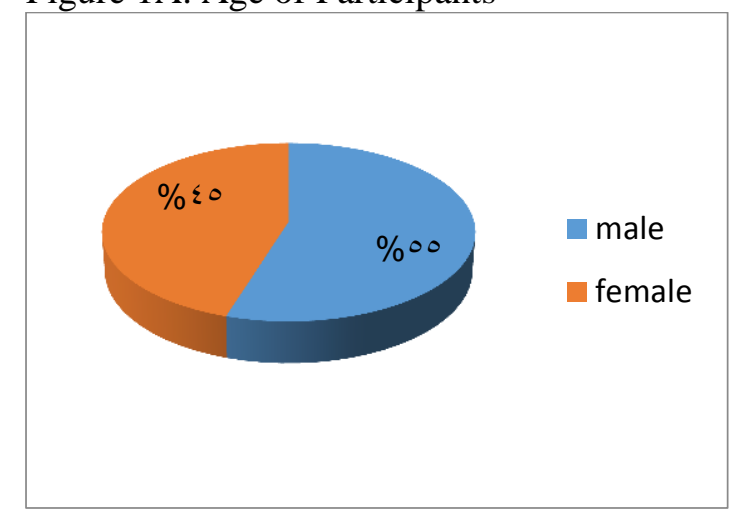

Figure 1B Marital status of participants

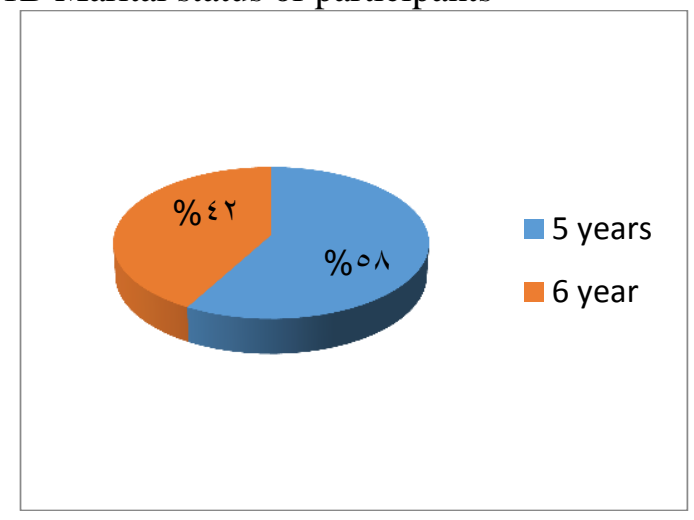

Figure 1D Year of study of participants.

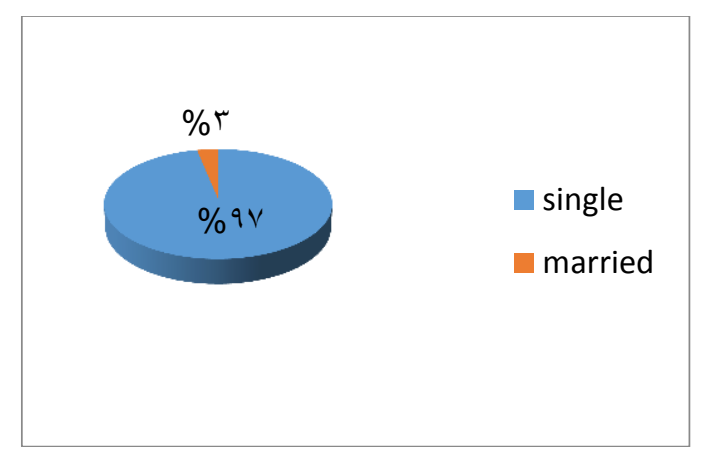




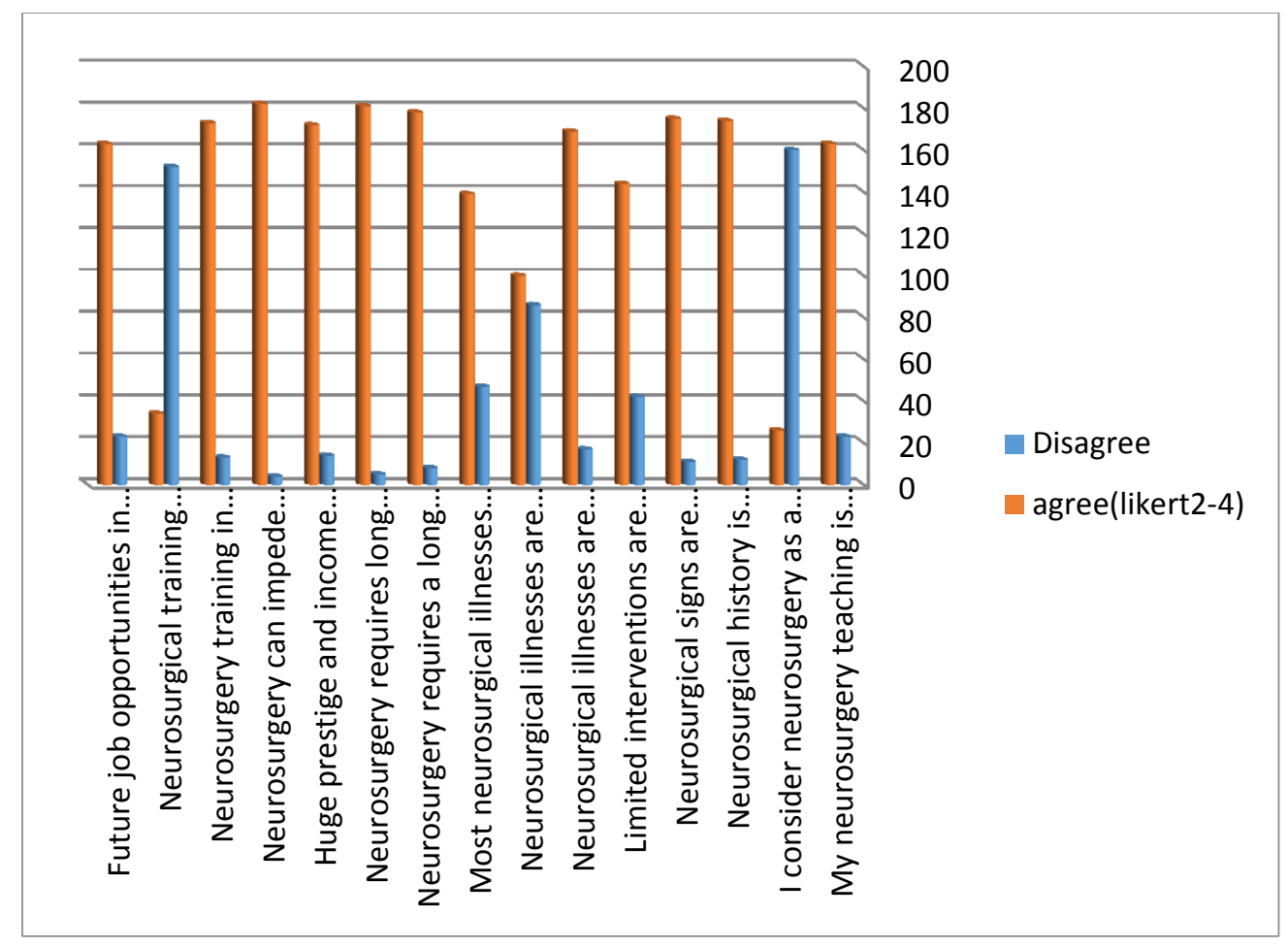

Figure 2 Likert scale distribution: disagree versus agree.

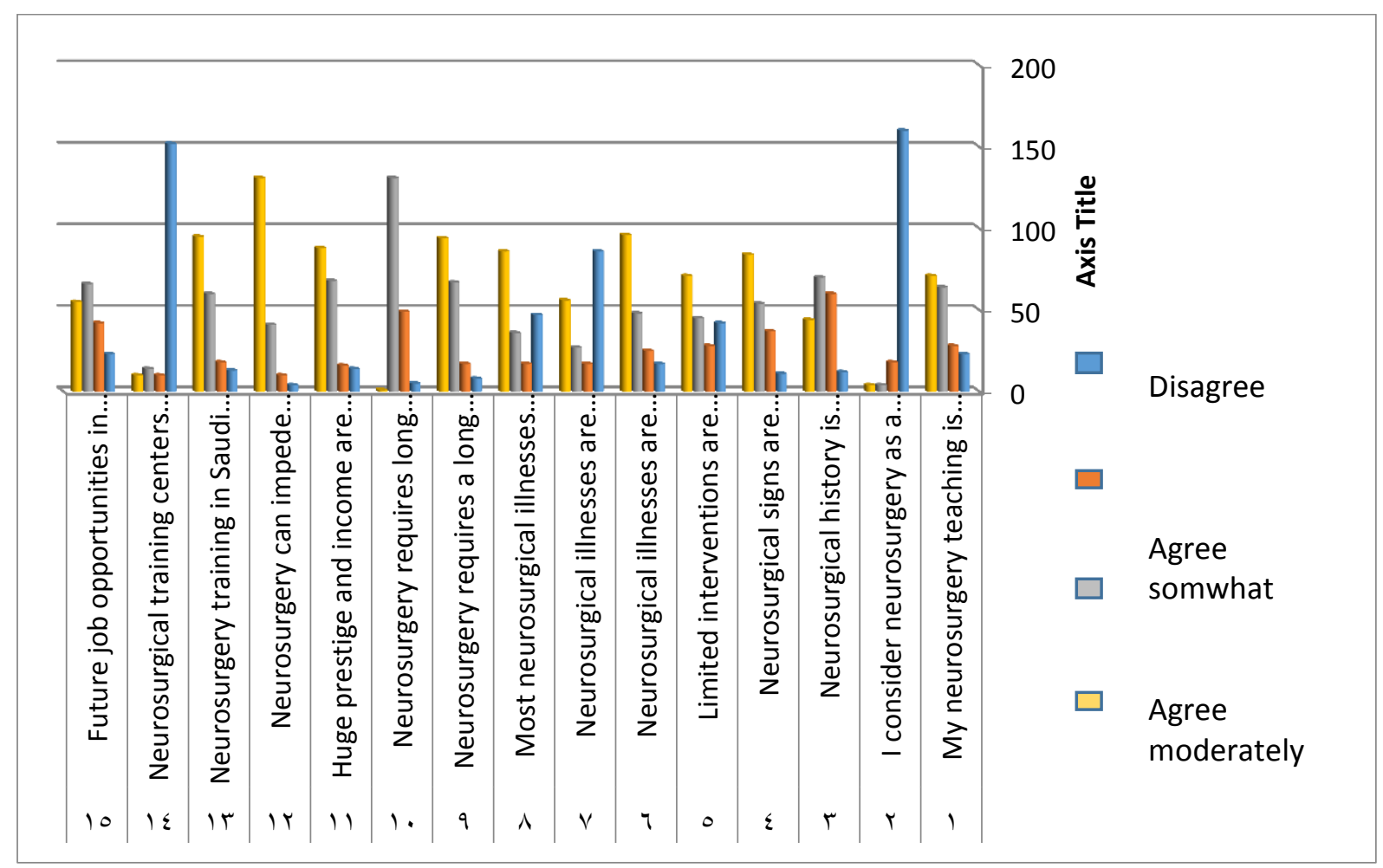

Figure 3 Likert scale distribution: disagree versus agree somewhat versus agree moderately versus agree strongly.

Discussion

In this study, the results were similar in some ways to one study published in Ireland. We tried to explore future career interests for medical students approaching internship year in neurosurgery and what are the factors influencing their choices. Unexpectedly, the findings of our study show that $97 \%$ of the medical students are not considering neurosurgery as their future 
career. Whereas, an Irish study showed that $78 \%$ of the last year medical student considering neurosurgery to be their ultimate career ${ }^{5}$. Multiple factors have been shown in the deviation of medical students' interest away from neurosurgery including controllable lifestyle, length of residency program, income and job opportunities. Taking in similarly, married and $90.5 \%$ of the students participated of our study and $85 \%$ of participants of the Irish study found that lifestyle changes and long residency program are the most important factors while choosing their future specialty in medicine. Few training centers as a factor had limited effect on career choice $18.3 \%$.

Conversely, several studies have confirmed that the clinical role models have a denotative influence on medical students' preferences $^{6,7,8}$. Around $53.8 \%$ of the participants believe that Neurology and Neurosurgery are challenging and interesting specialties which can nourish and satisfy their ambitions. Moreover, high prestige and income play a major role in choosing neurosurgery which is agreed by $92.5 \%$ of the participants.

Finally, globally, neurosurgery remains one of the most competitive specialties that attract top graduated students ${ }^{5}$. Nevertheless, locally in KSAU-HS, majority of the students are not considering neurosurgery as their ultimate career under the effect of many debatable factors.

\section{Conclusion}

Students show a deviation from neurosurgery as a future career perhaps the result is that's a difficult specialty that require long working hours, long training period, difficult diseases and poor prognosis and most importantly that it can impede family life. A study on a larger sample and preferably multicenter is required to generalize the results.

Acknowledgement: We would like to acknowledge and show our sincere gratitude and thank Dr. Sara Ghasham AlQahtani for her great effort in Data collection.

\section{References}

1. Miller G, Bomboat ZM, Allen F, Biernacki P, Hopkins MA, Gouge TH, Riles TS (2004): Impact of mandatory resident hour limitations on medical students' interest in surgery. J Am Coll Surg., 199:615-19.
2. Arnold MW, Patterson AF, Tang AS (2005): Has implementation of the 80 -hour work week made a career in surgery more appealing to medical students? Am J Surg., 189:129-33.

3. Chung RS (2005): How much time do surgical residents need to learn operative surgery? Am J Surg., 190:351-3.

4. Dorsey ER, Jarjoura D, Rutechi GW (2005): The influence of controllable lifestyle and sex on specialty choices of graduating U. S medical students, 1996-2003.Acad Med., 80:791-6.

5. Akhigbe T, Sattar M (2014): Attitudes and perceptions of medical students toward neurosurgery. World Neurosurg, 81(2):226-8.

6. Saigal $P$, Takemura $Y$, Nishiue $T$, Fetters MD (2007): Factors considered by medical students when formulating their specialty preferences in Japan: Findings from a qualitative study. BMC Med Educ., 7:31.

7. Burack JH, Irby DM, Carline JD, Ambrozy DM, Ellsbury KE, Stritter FT et al. (1997): A study of medical students' specialty-choice pathways: Trying on possible selves. Acad Med., 72:534-41.

8. Henderson MC, Hunt DK, Williams JW Jr (1996): General internists influence students to choose primary care careers: The power of role modeling. Am J Med., 101:648-53. 